\title{
O ENSINO REGULAR DA CALIGRAFIA: A EXPERIÊNCIA DA ESCOLA AMERICANA DE CURITIBA NO FINAL DO SÉCULO XIX E INÍCIO DO SÉCULO XX'.
}

\author{
Geysa Spitz Alcoforado de Abreu ${ }^{2}$ \\ Universidade Estadual de Santa Catarina - UDESC \\ geysa.abreu@uol.com.br
}

\begin{abstract}
RESUMO
Este trabalho examina uma experiência de ensino da escrita, do final do século XIX às primeiras décadas do século XX, partindo da análise das transformações sofridas no ensino regular da caligrafia na Escola Americana de Curitiba. No processo de alfabetização, ainda no século XIX, a escrita adquiriu o mesmo estatuto da leitura, devendo ser ensinada simultaneamente, em substituição ao ensino sucessivo, onde o aluno primeiro aprendia a ler para depois aprender a escrever. Na Escola Americana de Curitiba, o método utilizado para o ensino da escrita sofreu alterações ao longo dos anos. Em 1892, distanciando-se dos métodos utilizados na maioria das escolas brasileiras da época, nas quais os alunos aprendiam a escrever cobrindo o traçado do professor, os alunos principiantes começavam a escrever primeiro em suas lousas, para depois passar para o traçado a lápis nos livros em branco; nas séries seguintes, utilizava-se a pena. Nos Estados Unidos, na virada do século, visando atender às necessidades do mundo em transformação, surgiu a proposta da caligrafia muscular. Na década de 1920, há indicativos de que já estivesse em uso na Escola Americana de Curitiba um método americano de caligrafia muscular, "The Palmer Method of Business Writing", que continuaria a ser empregado até a década de 1950.

Palavras-chave: Cultura escolar; Escola Americana; Ensino de Caligrafia; História da Educação; Paraná.
\end{abstract}

\section{THE REGULAR TEACHING OF CALLIGRAPHY: THE EXPERIENCE OF THE AMERICAN SCHOOL IN CURITIBA IN THE LATE XIX CENTURY AND EARLY XX CENTURY}

\begin{abstract}
This work examines an experience of teaching writing, between the end of the XIX century and the first decades of the XX century, based on the analysis of the changes in the regular teaching of calligraphy in the American School in Curitiba. Still in the XIX century, in the process of alphabetization, writing acquired the same status of reading and should be taught simultaneously, replacing the successive teaching, where the student first learned to read and just later learned to write. In the American School in Curitiba, the method used for the teaching of writing was changed across the years. In 1892, distancing itself from the methods used in most of Brazilian schools at the time, where students learned to write filling the route of the teacher, beginner students first began to write in their slates, and later would move towards pencil tracing in blank books; in the following grades, feathers were used. In the United States at the turn of the century, aiming to meet the needs of a changing world, the proposal of muscular calligraphy emerged. In the decade of 1920 there are signs that a method of muscular calligraphy was already in use at the American School in Curitiba, "The Palmer Method of Business Writing", which would continue to be used until the decade of 1950.
\end{abstract}

Keywords: School culture; American School; calligraphy teaching; history of education; Paraná. 


\section{Introdução}

Até meados do século XIX, a educação era entendida como uma "arte". Sendo uma arte, não se tratava de uma atividade exercida sem teoria, mas um produto tanto da experiência tradicional transmitida, quanto o resultado da experiência pessoal de cada indivíduo, adquirida pelo mestre no exercício de sua profissão. No final do século XIX, as discussões em torno da educação visavam a constituição de uma "ciência" da educação. As novas propostas aspiravam superar os limites da "tradição", substituindo-os pela ciência. Como ciência, pretendia-se dar uma direção mais eficaz e verificação mais concreta de seus resultados. Nesse contexto, o ensino da leitura e da escrita passa a ocupar uma posição relevante nos estudos sobre a educação em diversos países.

O movimento de renovação pedagógica que se processa a partir da segunda metade do século XIX, tenta investir contra o caráter abstrato e pouco utilitário da instrução, prescrevendo novos métodos, materiais, variação das atividades pedagógicas etc. No processo de alfabetização, a escrita adquiriu o mesmo estatuto da leitura, devendo ser ensinada simultaneamente, em substituição ao ensino sucessivo, onde o aluno primeiro aprendia a ler para depois aprender a escrever. Experiências e alterações nas práticas escolares foram sendo produzidas provocando uma maior racionalização do processo educativo.

Este trabalho examina uma experiência de ensino da escrita manual, visando apreender como se produziram modificações nas práticas escolares. Para tanto, foi analisado o ensino regular da caligrafia realizado na Escola Americana de Curitiba, desde o final do século XIX até as primeiras décadas do século XX.

Para compreender essa experiência que teve origem no interior de uma denominação do protestantismo norte-americano, sendo por isso um elemento para a compreensão do "americanismo" na educação, a história da Instituição foi analisada na perspectiva da cultura escolar, entendendo-a como a definiu JULIA (2001, p. 10),

[...] como um conjunto de normas que definem conhecimentos a ensinar e condutas a inculcar, e um conjunto de práticas que permitem a transmissão desses conhecimentos e a incorporação desses comportamentos; normas e práticas coordenadas a finalidades que podem variar segundo as épocas (finalidades religiosas, sociopolíticas ou simplesmente de socialização).

Nessa perspectiva, o questionamento que orientou este trabalho esteve voltado para os aspectos internos da escola, sem desconsiderar as relações da cultura escolar com culturas que lhe são contemporâneas. Segundo VIÑAO-FRAGO (1998, p.179),

[...] el núcleo de la cultura escolar lo constituyen un conjunto de prácticas o pautas de comportamiento con un cierto grado de consolidación institucional [...] Se trata, en definitiva, de modos de actuar generados en y por la propia institución - o sea, relativamente autónomos - que pueden compartirse con otros similares - formando, en este caso, una cultura institucionalmente más amplia, y que se refieren tanto al conjunto de la organización y relaciones que tienen lugar en el seno de la misma, fuera de las aulas, como, de un modo más específico, a aquello que se ha denominado "la marcha de la clase", el "cuerpo a cuerpo" con el que cada profesor y cada alumno hacen frente a su tarea diaria en el aula. 
Entendendo-se que a escola é uma instituição social produtora de práticas e representações que amplia, adapta e recria a cultura inclusiva, o estudo do conjunto das características que compõe o modo escolar de transmissão cultural num tempo e espaço definidos, possibilita a compreensão de elementos não priorizados pela historiografia tradicional. Assim, segundo WARDE \& CARVALHO (2000, p.16),

[...] a ênfase da nova historiografia na materialidade das práticas, dos objetos e de seus usos produz um novo modo de olhar e interrogar as fontes disponíveis. Um novo padrão de visibilidade torna visível aquilo que as representações cristalizadas na historiografia educacional relegavam à invisibilidade do não dito e, portanto, não exposto. Aquilo que, no discurso em que se articulam tais representações, não é preciso dizer porque não é preciso fazer ver.

A principal base documental desse trabalho foi extraída do acervo da Escola Americana de Curitiba $^{3}$, composto por uma extensa e variada documentação, tais como: rascunhos manuscritos de relatórios enviados pelos missionários presbiterianos aos dirigentes da Missão; Livros de matrículas; Livros-caixa; manuscritos diversos; correspondências; relação das obras da biblioteca; plantas arquitetônicas; livros de chamada (diversos); materiais didáticos; recortes de jornais da época; fotografias, dentre outros. A variedade e a riqueza de informações que essas fontes apresentam, ilustram a fecundidade dos arquivos escolares para as pesquisas em história da educação ${ }^{4}$.

\section{A Escola Americana de Curitiba ${ }^{5}$}

A Escola Americana de Curitiba foi fundada em 1892 por missionáriaseducadoras norte-americanas: Miss Mary Parker Dascomb e Miss Elmira Kühl, enviadas ao Brasil pela American Foreign Board - Junta Missionária de Nova Iorque, ligado à Igreja Presbiteriana do Norte dos Estados Unidos. A educação era um meio de evangelização indireta amplamente utilizada pelos presbiterianos nos Estados Unidos e a criação de escolas no Brasil, com auxílio do Board de Nova Iorque, visava auxiliar na difusão dos princípios religiosos e valores culturais inerentes ao presbiterianismo.

A Escola Americana de Curitiba, que começou como uma filial da Escola Americana de São Paulo ${ }^{6}$, pode ser considerada uma expressão da pedagogia presbiteriana norte-americana, observada também em outras escolas criadas no Brasil por missionários presbiterianos, no mesmo período. Tais escolas, segundo HILSDORF (1986), representavam "a ponta de lança que abriria caminho para uma renovação das mentalidades e das práticas pedagógicas e, por extensão, da sociedade brasileira", pois materializavam alguns aspectos do sistema educacional norte-americano tão "caros" à época.

A Escola Americana de Curitiba seguia as diretrizes educacionais estabelecidas para a Escola Americana de São Paulo, adotando, inclusive o mesmo calendário. O trabalho escolar foi dividido em três níveis: Primário, Intermediário e Secundário; e existia, ainda, a Classe Normal. A Escola atendia alunos de diversas nacionalidades, mas a maioria era brasileira. As aulas eram ministradas em Português; possuía um plano de curso; apresentava uma estrutura seriada, com lições graduadas e progressivas; adotava o sistema de co-educação; empregava o método intuitivo, considerado a base do ensino moderno; possuía um corpo docente qualificado; material e mobiliário moderno, oriundo dos Estados Unidos etc. 
Para o ensino da leitura e escrita utilizavam diversos recursos materiais, tais como: a lousa, letras impressas em papelão para a manipulação das crianças, a lousa individual, livros de leitura, livros de poesia, cadernos em branco, cadernos com linhas preparadas para caligrafia, lápis, a pena, jornais e revistas, entre outros. A escola possuía biblioteca com obras em português, inglês, alemão e francês (cf. ABREU, 2003).

\section{O ensino da escrita na Escola Americana de Curitiba}

Na Escola Americana de Curitiba, o método utilizado para o ensino da escrita sofreu alterações ao longo dos anos. As informações encontradas no acervo da escola permitem recuperar, ainda que parcialmente, as práticas e objetos utilizados.

O programa de ensino da Escola Americana de Curitiba foi detalhado num manuscrito não datado que, provavelmente, remonta ao ano de 1893. De acordo com tal documento, o Primário estava dividido em duas classes: Primário A e Primário B. O nível Intermediário, também estava dividido em duas classes, A e B. Elas eram combinadas "para achar o tempo para ter a Classe Normal" (cf. manuscrito c1893, apud ABREU, 2003).

Distanciando-se dos métodos utilizados na maioria das escolas brasileiras da época, nas quais os alunos aprendiam a escrever cobrindo o traçado do professor, desde a fundação da Escola Americana, em 1892, os alunos principiantes começavam a escrever primeiro em suas lousas, para depois passar para o traçado a lápis. As aulas de caligrafia faziam parte do programa de todas as classes, desde o primário até o secundário. As lições eram graduadas e progressivas.

No primeiro ano do curso primário, nas aulas de caligrafia, os alunos começavam a escrever primeiro nas suas lousas. Na seqüência, passavam a escrever a lápis, nos livros em branco, principiando com as letras mais fáceis do livro de leitura. Passavam então a copiar "da grande pedra" e, mais tarde, de cartões do livro. "Ensina-se a criança a saber bem a palavra, antes de escrevê-la, não é permitido a copiar letra por letra". Essa informação revela a preocupação com a ortografia desde o início do aprendizado da escrita (cf. ABREU, 2003).

Ainda no primeiro ano, os alunos tinham aulas de ditado, que consistia em cópia da "lição de leitura escrita na lousa". Nas aulas de ditado, os alunos também utilizavam cadernos com linhas para caligrafia: "tudo está escrito nas linhas preparadas para a caligrafia" (manuscrito de c1893, apud ABREU, 2003).

No segundo ano do curso primário os alunos já utilizavam a pena nas aulas de caligrafia. Ensaiavam o traçado de "letras simples minúsculas e maiúsculas, segundo sua derivação", depois, palavras curtas "principiando com letras minúsculas com e sem acentos". Por fim, copiando dos cartões do livro com a pena, "acostumam-se a escrever a frase inteira de memória".

No curso intermediário, curiosamente, os documentos da escola informam que a caligrafia era ensinada de acordo com o sistema alemão, "contando cada parte da letra" (rel. manuscrito c1893; rel. manuscrito de 1895, apud ABREU, 2003). Supõe-se que se ensinava aos alunos a caligrafia utilizando a letra gótica, também conhecida como "letra preta", adotada na Alemanha, desde o surgimento da imprensa, como tipo principal. Sabese, por exemplo, da existência e circulação em Curitiba de Bíblias em alemão, impressas em letra gótica. Esse dado permite supor que a decifração de diferentes tipos de caligrafia fosse uma habilidade necessária para a época. Quanto ao domínio do traçado de diferentes tipos de letras, talvez fosse considerado como um pré-requisito para outras aprendizagens. 
A importância atribuída à decifração de diferentes caligrafias e diferentes manuscritos pode ser aferida também pela informação a respeito do longo ciclo de vida de paleógrafos ${ }^{7}$ junto à produção e o mercado brasileiros, desde meados do séc. XIX aos anos 60 do século XX, fenômeno similar ao que ocorreu na Espanha, conforme informa BATISTA (2002).

Ainda de acordo com BATISTA (2002), no Decreto 3.405, de 15/01/1912, que aprova o Programa de Ensino dos Grupos Escolares e demais escolas públicas de Minas Gerais, é prescrita, para as aulas de leitura do $3^{\circ}$ ano, a "leitura variada de manuscritos" e, para o $4^{\circ}$ ano, a "leitura de manuscritos".

Não dispomos ainda de estudos que permitam avaliar o grau de prevalência da "cultura manuscrita" num período no qual o impresso vai, aos poucos, se tornando dominante. Contudo, conforme salienta BATISTA (2002), no Brasil, até muito recentemente,

[...] os documentos públicos eram obrigatoriamente manuscritos. Sabe-se, também, que práticas comerciais exigiam um intensivo uso do manuscrito na escrituração contábil e na correspondência comercial. Sabe-se, ainda, que, na vida privada, o cotidiano das camadas letradas envolvia uma intensa troca epistolar, assim como, nos usos femininos da escrita, a cópia e circulação intensa de receitas, "pensamentos", poemas, letras de música. Sabe-se, além disso, que em todo o processo de elaboração dos textos a serem impressos, nas esferas política, literária, jurídica, religiosa e científica, a redação e a cópia manuscritas constituíam etapas prévias à impressão, envolvendo mesmo um circuito, ainda que mais restrito, de comunicação de textos.

Na Escola Americana de Curitiba, no primeiro ano do curso intermediário, nas aulas de caligrafia, ensinava-se as "letras minúsculas e maiúsculas nos espaços largos". Como reforço às tarefas de sala, os alunos levavam exercícios para praticar em casa, onde deveriam escrever "dentro de espaços marcados, contando cada parte da letra". Praticavam também os "zeros simples e combinados" (manuscrito c1893, apud ABREU, 2003).

No segundo ano do curso intermediário, os alunos começavam a escrever "letras maiúsculas e minúsculas nos espaços menores, contando cada parte da letra, palavras com e sem acentos etc. Zeros simples e combinados..." As lições de caligrafia eram enviadas para casa duas vezes por semana e exigia-se que fossem "feitas com muito capricho" (manuscrito c1893, apud ABREU, 2003).

Nos documentos da Escola Americana de Curitiba, não foram localizadas informações sobre o ensino da escrita no início do século XX. Sabe-se apenas que a caligrafia continuou a fazer parte do programa de todas as séries, o que revela a importância atribuída a essa matéria. Os diários de classe de professoras da primeira e quartas-séries informam que, até 1920, a caligrafia era ensinada em todos os dias da semana, mas não há registros detalhados sobre o método utilizado.

De acordo com VIDAL \& GVIRTZ (1998, p. 19), em 1904, nos programas de ensino paulistas, a caligrafia norte-americana, ou inclinada, aparece como a mais indicada para o trabalho escolar:

Os exercícios de caligrafia acompanham as lições de leitura; assim, os alunos começarão, desde o primeiro dia de aula, a copiar letras, palavras e pequenas sentenças. Ao professor incumbe observar e corrigir a posição dos dedos e do corpo. No primeiro ano os exercícios serão feitos, no primeiro semestre, nas ardósias e, no segundo, no papel, com lápis. Do 
segundo ano em diante, serão usados os cadernos, cujo tipo principal de letra seja a norte-americana, completando-se este ano com o ensino de letras de fantasia (DECRETO 1217, de 19/04/1904).

Anos depois, a caligrafia inclinada passou a ser criticada e apontada como uma das causas para os problemas de miopia e escoliose, encontrados nos alunos (VIDAL, 1998).

No que se refere ao ato de escrever, a pedagogia começou a produzir estudos que buscavam incorporar os avanços no campo da Higiene. Passou-se a prescrever regras quanto à posição correta do aluno, do papel, a como segurar o lápis, ao tamanho correto das carteiras etc.

No Brasil, segundo VIDAL (2000, p. 499), “a fórmula de George Sand - "papel direito, corpo direito, escrita direita" - foi evocada pelos educadores na defesa da caligrafia vertical ${ }^{8}$. O novo tipo caligráfico apresentava-se como "o mais adaptado aos signos da modernidade", apresentando-se como "rápido, econômico e higiênico". Esse novo tipo caligráfico permitia a posição correta do aluno durante o ato da escrita, evitando as deformidades do corpo provocadas ao executar letras inclinadas ou oblíquas (cf. VIDAL \& GVIRTZ, 1998). A caligrafia vertical parecia ter substituído a escrita inclinada do início do século, impondo um tipo caligráfico homogêneo para todo o território brasileiro.

Nos Estados Unidos, na virada do século, os estudos a respeito da escrita passam a considerar outras questões quanto ao ato de escrever. Visando atender às necessidades do mundo em transformação, surgiu a proposta da caligrafia muscular. Segundo VIDAL \& GVIRTZ (1998, p. 19), no Brasil, a discussão a respeito do tipo ideal de escrita foi retomada nos anos 1930, devido a experiências com a caligrafia muscular no Rio de Janeiro. As autoras informam que esta proposta teria chegado ao Brasil na década de 1920, com a introdução do método no Colégio Mackenzie (cf. VIDAL, 2000, p. 500).

No acervo da Escola Americana de Curitiba, encontram-se vários exemplares de um método de ensino de caligrafia americano, intitulado: "The Palmer Method of Business Writing",

Trata-se de um método de caligrafia muscular, provavelmente introduzido na década de 1920, que continuou a ser utilizado na Escola Americana até a década de $1950{ }^{10}$. A proposta do método Palmer era tornar o ato de escrever menos "angustiante" para os alunos.

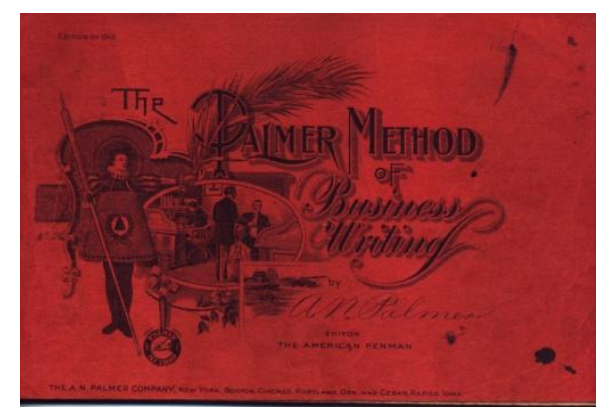

Figura 1 - Capa do Método Palmer

O método Palmer criticava o sistema usado em algumas escolas americanas, no qual a criança deveria escrever por "longas e tristes" páginas dos copy-books ${ }^{11}$. O sistema anterior era criticado porque exigia uma ação lenta dos dedos na formação das letras, dando um grau justo de precisão. Além disso, a escrita impecável, perfeita, apresentada no topo das páginas dos copy-books, constrangia os alunos, posto que não lhes era possível 
reproduzir fielmente o modelo, sendo, por isso, desfavorável ao processo de aprendizado da escrita. A demora para a execução dos textos evidenciava que o sistema era viável somente para a escrita de trechos curtos. Em contrapartida, o método Palmer, um método de caligrafia muscular, se apresentava como mais apropriado à sociedade moderna, por permitir "legibilidade, rapidez, facilidade, sem sofrimento". A base do novo método era a "liberdade de movimento". O autor ressaltava a importância de uma postura correta e confortável para obter uma boa caligrafia. Segundo ele, "a caligrafia muscular significaria uma postura correta e saudável, coluna ereta, olhos distantes o suficiente do papel e os ombros na mesma altura."

A obra adota uma retórica pedagógica, simulando uma conversa entre o autor e os alunos, na qual o autor fornece as instruções necessárias para a utilização do método.

Nas instruções iniciais o autor sugere um modelo de exercício que o aluno deveria executar antes de iniciar o estudo, para servir de parâmetro para avaliação de seu progresso. Em seguida, alertava quanto ao uso de roupas apropriadas, ou seja, roupas que não impedissem a livre movimentação do braço direito.

As lições eram apresentadas passo a passo e diversos diagramas ilustravam as explicações. A primeira lição do método era: ensinar aos alunos a posição apropriada para escrever. Para isso o método apresentava fotografias indicando a forma correta de segurar a caneta, o posicionamento do papel e do livro, que deveria ser mantido aberto durante a execução do exercício, a postura do aluno na carteira, fotos de salas de aulas com alunos praticando a escrita (Figura2) etc.

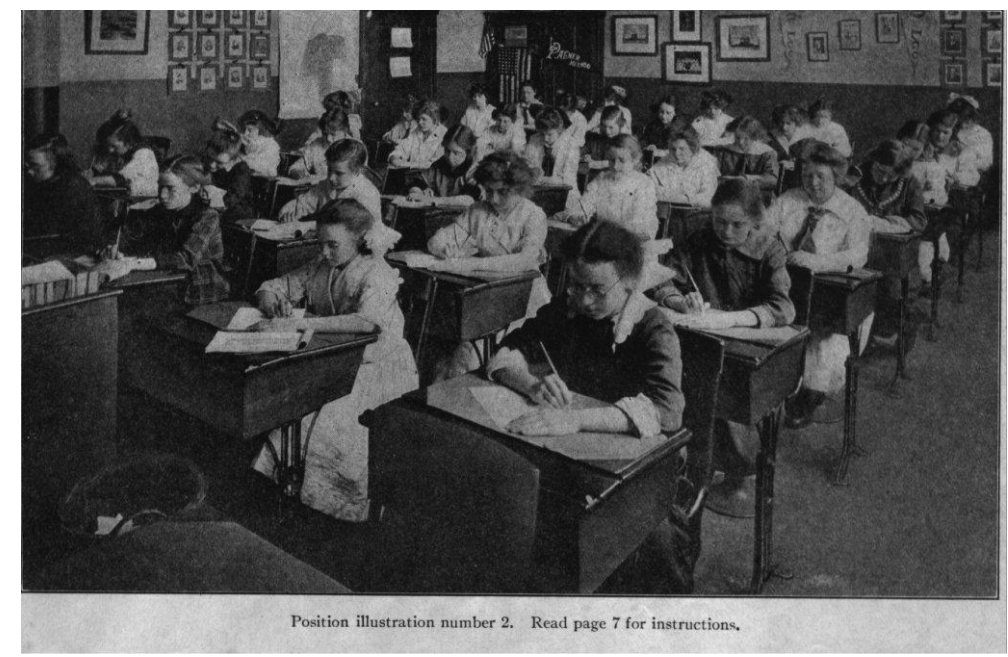

Figura 2 - página do método Palmer

A segunda lição tratava do treinamento físico necessário à prática da caligrafia. A postura correta, exercícios de relaxamento, prática de movimentos, a forma correta de segurar a caneta era ensinada por meio de ilustrações e diagramas. Somente na quarta lição, iniciavam-se os exercícios de escrita.

Após as aulas de postura, o aprendizado era iniciado por meio de exercícios preparatórios, para treinar a movimentação do papel. Nos diagramas abaixo (Figura 3), a letra A representa o ângulo reto do cotovelo e sua posição na carteira; B é o apoio muscular do antebraço; $\mathrm{C}$ é a posição da mão esquerda em relação ao papel; a letra D representa a caneta (pen holder); e a letra E, a linha imaginária através da qual a caneta deve deslizar, em movimentos ascendentes e descendentes. 


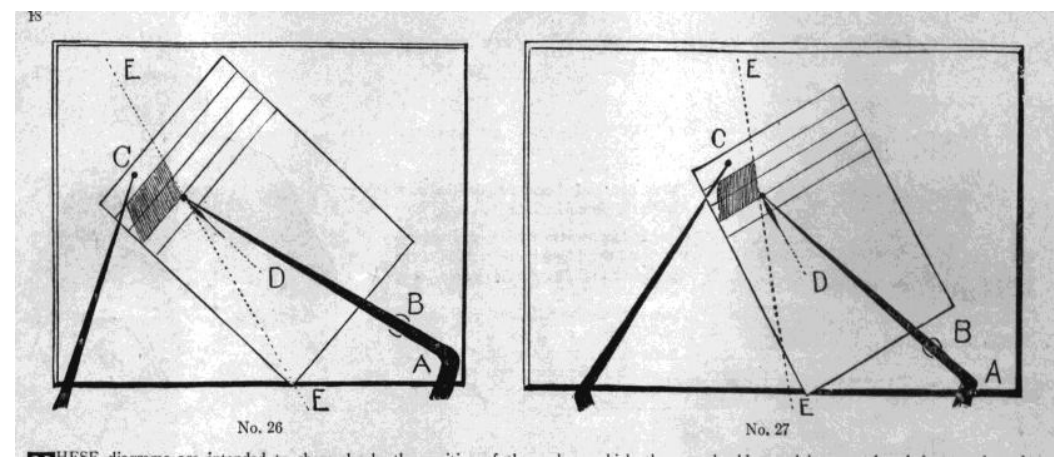

Figura 3 - Diagramas do Método Palmer

Com o antebraço direito atravessando a borda inferior do papel, a caneta poderia percorrer o espaço equivalente a $1 / 4$ ou $1 / 3$ da largura do papel, antes que a posição do papel fosse mudada. A mudança da posição do papel deveria ser feita com a mão esquerda. Portanto, um papel de $8 \times 10$ 1/2 polegadas seria movido três a quatro vezes durante o percurso percorrido pela caneta na largura. Quando o final da linha fosse atingido, o papel deveria retornar a posição inicial, sendo movido para cima, na mesa, com a distância de uma linha (cf. Método Palmer apud ABREU, 2003).

Os exercícios previam movimentos da caneta em diversas direções. As lições não eram realizadas em "linhas preparadas para a caligrafia", que delimitam o tamanho da letra que deveria ser escrita pelos alunos. Tampouco existia um modelo no topo da página para ser imitado. O método pretendia, desta forma, "respeitar a individualidade dos alunos".

O método estava organizado numa seqüência de 146 lições. As lições incluíam exercícios para desenvolver a habilidade motora, passando para o traçado de letras do alfabeto isoladas e emendadas, números, letras e palavras e frases. Por meio de uma série constantemente repetida de exercícios (drills) rápidos, a aplicação do movimento se tornaria um hábito fixo do estudante (Figuras 4 e 5).

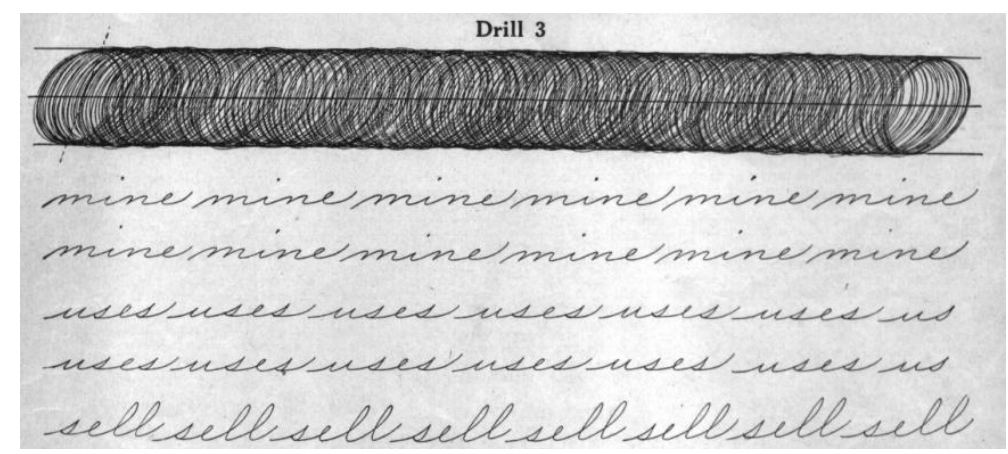

Figura 4 - Exercício n. 3

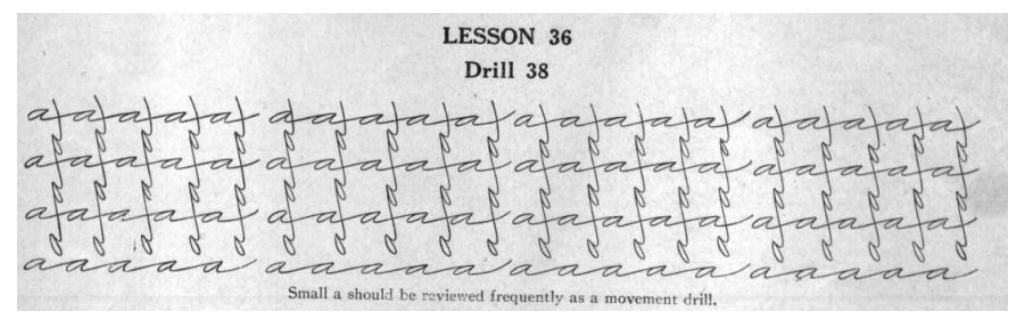

Figura 5 - Exercício n. 38 
Existia nos Estados Unidos um centro de pesquisas para acompanhar o resultado da aplicação do método e, para tanto, os autores solicitavam que se enviasse para o centro de pesquisas amostras de exercícios efetuados e o tempo despendido para a sua realização.

\section{Considerações Finais}

Este texto procurou expor, de forma sintética, uma das práticas da Escola Americana de Curitiba, a do ensino regular da caligrafia, empregada durante toda a existência da escola, em todas as séries, inclusive no Curso Secundário; bem como algumas transformações metodológicas que esse ensino sofreu.

No que se refere à educação escolar presbiteriana, ainda existem muitas lacunas a respeito do funcionamento interno das escolas instaladas no Brasil a partir da segunda metade do século XIX.

Embora a educação escolar presbiteriana já tenha sido temática de diversos trabalhos, a maioria dos estudos publicados não se volta para a análise dos aspectos internos das instituições educativas. Na tentativa de suprir esta lacuna, este estudo adotou uma perspectiva nova e de maior alcance explicativo. Assim, operando com o conceito de "cultura escolar", foram exploradas fontes diretamente escolares que, por serem expressão das práticas escolares cotidianas, possibilitaram a apreensão do processo de constituição de um determinado padrão escolar. A riqueza de informações que essas fontes apresentam, reafirma a fecundidade dos arquivos escolares para as pesquisas em história da educação.

\section{Referências}

ABREU, Geysa Spitz Alcoforado de. Escola Americana de Curitiba (1892-1934): um estudo do americanismo na cultura escolar. Dissertação de mestrado. PUC/SP. 2003.

O ensino regular da caligrafia: a experiência da Escola Americana de Curitiba no final do século XIX e início do século XX In: III Congresso Brasileiro de História da Educação, 2004, Curitiba. A educação escolar em perspectiva histórica. Curitiba-PR: Editora Universitária Champagnat, 2004. v.01. p.250.

Fecundidade, desafios e possibilidades do uso de arquivos escolares como fonte para pesquisas de História da Educação. Revista de Educação FABE, v. 1, p. 69-74, 2010.

BATISTA, Antônio Augusto Gomes. Paleógrafos ou livros de leitura manuscrita: elementos para o estudo do gênero. Memória da leitura, Campinas, SP: Instituto de Estudos da Linguagem. 2002. Disponível em: http://www.unicamp.br/iel/memoria/Ensaios/Batista/ batista.htm. Acesso em 27 ago. 2004.

BARBANTI, Maria Lúcia Spedo Hilsdorf. Escolas americanas de confissão protestante na Província de São Paulo: um estudo de suas origens. Dissertação de mestrado, Faculdade de Educação, da Universidade de São Paulo. 1977.

HILSDORF, Maria Lúcia Spedo. Francisco Rangel Pestana: jornalista, político, educador. Tese de doutorado, Faculdade de Educação da Universidade de São Paulo. 1986. 
JULIA, Dominique. A Cultura escolar como objeto histórico. Revista Brasileira de História da Educação. Tradução: Gizele de Souza. São Paulo: Autores Associados, n. ${ }^{\circ}$ 1, janeiro/junho, pp.9-43. 2001.

VIDAL, Diana G. Da caligrafia à escrita: experiências escolanovistas com caligrafia muscular nos anos 30. Revista da Faculdade de Educação, São Paulo, v. 24, nº1, p. $126-$ 140, jan./jun. 1998.

Escola Nova e processo educativo. In: LOPES, Eliane Marta Teixeira; FARIA FILHO, Luciano Mendes; VEIGA, Cynthia Greive (orgs.) 500 anos de Educação no Brasil. Belo Horizonte: Autêntica Editora. 2000.

VIDAL, Diana Gonçalves; Gvirtz, Silvina. O ensino da escrita e a conformação da modernidade escolar: Brasil e Argentina (1880-1940). Revista Brasileira de Educação, no 08, mai/jun/jul/ago. 1998.

VIÑAO FRAGO, Antônio; ESCOLANO, Augustin. Currículo, espaço e subjetividade: a arquitetura como programa. Tradução: Alfredo Veiga Neto. Rio de Janeiro: DP\&A. 1998.

WARDE, Mirian Jorge. Americanismo e Educação: a fabricação do "homem novo". Projeto de pesquisa desenvolvido no Programa EHPS, com apoio da Capes e do CNPq. 2001.

WARDE, Mirian Jorge; CARVALHO, Marta Maria Chagas de. Política e cultura na produção da História da Educação no país. Contemporaneidade e Educação: revista semestral de Ciências Sociais e Educação, Rio de Janeiro, 2000, ano V, n. ${ }^{\circ}$ 07, pp. 09-33.

Notas:

\footnotetext{
${ }^{1}$ Este trabalho foi apresentado no III Congresso Brasileiro de História da Educação, em Curitiba, em 2004.

${ }^{2}$ Professora Adjunta do Centro de Ciências Humanas e da Educação (FAED) da Universidade do Estado de Santa Catarina. Doutora em Educação pela PUC-SP.

${ }^{3}$ Trata-se de um acervo privado, mantido pela família do ex-proprietário da escola.

4 Uma descrição detalhada do acervo e das fontes utilizadas encontram-se em artigo intitulado: "Fecundidade, desafios e possibilidades do uso de arquivos escolares como fonte para pesquisas de História da Educação" (ABREU, 2010).

${ }^{5}$ A história dessa instituição foi apresentada como dissertação de mestrado, intitulada "Escola Americana de Curitiba (1892-1934): um estudo do americanismo na cultura escolar", defendida na Pontifícia Universidade Católica de São Paulo.

${ }^{6}$ Posteriormente denominada Mackenzie College.

${ }^{7}$ O termo é aqui empregado como "livro escolar destinado ao aprendizado na leitura da letra manuscrita". Segundo Batista (2002) esse tipo de livro foi bastante difundido na instrução elementar no Brasil, ao longo do século XIX e nas primeiras décadas do século XX. Tratava-se de um "livro manuscrito, ainda que impresso,
} 
em que cada lição ou novo texto é reproduzido com uma letra ou escrita diferente, dispostos dos de leitura mais fácil à mais difícil. Um livro, portanto, para ensinar, ao que tudo indica, dentre outras coisas, a decifração de diferentes caligrafias e diferentes manuscritos" (Batista, 2002).

${ }^{8} \mathrm{Na}$ Reforma da Instrução Primária de Minas Gerais, em 1906, a caligrafia vertical foi a indicada; e em 1908, Francisco Vianna publicava sua primeira série de cadernos de caligrafia, com o tipo vertical (Cf. Vidal \& Gvirtz, 1998, p. 19).

9 PALMER, A. N. 1919. The Palmer Method of Business Writing. New York: editor of the American Penman. A primeira edição foi publicada em 1901.

${ }^{10}$ A Escola foi vendida em 1934, mas continuou funcionando, sob nova direção, até 1956.

${ }^{11} \mathrm{O}$ termo copy-book foi empregado durante muito tempo para designar "folhas de papel encadernadas juntas com uma capa, contendo no topo de cada página uma linha escrita ou um exercício para ser imitado pelos alunos nas linhas seguintes. Algumas vezes o cabeçalho era feito de cópias cuidadosamente desenhadas, mecanicamente perfeitas por meio de um sistema de gravação manual" (explicação do autor).

Recebido em: $\quad$ 30/04/11

Aprovado em: $14 / 06 / 11$ 